\title{
Saúde do idoso: análise dos indicadores básicos de saúde
}

Recebido: 28 jan 2019 Aceito: 10 fev 2019

Autor de correspondência: camargos99@hotmail.com

Conflito de interesses: Os autores declaram não haver nenhum interesse profissional ou pessoal que possa gerar conflito de interesses em relação a este manuscrito.
${ }^{(1)}$ Faculdade de Saúde Pública, Universidade de São Paulo - USP, São Paulo, SP, Brasil.

\section{Resumo}

Os indicadores de qualidade em saúde são um processo crítico-reflexivo, contínuo e sistemático sobre práticas e processos desenvolvidos no âmbito da saúde, sintetizados por indicadores de natureza quantitativa e/ou qualitativa. Sua finalidade é proporcionar informações fidedignas, dar suporte, sustentar a administração para auxiliar processos de tomada de decisão. Desta forma, os indicadores de qualidade em saúde são critérios fundamentais para julgar e comparar serviços, programas e políticas de saúde, ou seja, tais indicadores funcionam como parâmetros para avaliar a qualidade da assistência à saúde de uma população. Portanto, dada a complexidade de avaliação em saúde, os indicadores são importantes ferramentas para produzir informações adequadas sobre efeitos e os custos que envolvem o uso de tecnologias, programas ou serviços de saúde, inclusive no que diz respeito a saúde do idoso. Entretanto, um problema subjacente à consolidação das políticas de saúde do idoso no Brasil é a falta de mecanismos de monitoramento da implementação e avaliação dos resultados dos investimentos neste setor. O Brasil, apesar de ser considerado pioneiro na criação de leis e políticas públicas que visam à proteção social da pessoa idosa, tem dificuldades em monitorar e avaliar estas medidas em razão da ausência de indicadores sensíveis. Neste contexto, a alocação e distribuição alcança melhores resultados quando o planejamento em saúde contribui de maneira eficiente, utilizando as ferramentas disponíveis como diagnósticos epidemiológicos e das necessidades de saúde. Nesta perspectiva podemos afirmar que a política de saúde é eficaz e eficiente quando a ação planejada for realizada. No caso do Sistema Único de Saúde - SUS, é muito importante conhecer que os recursos financeiros são limitados e as necessidades são grandes e que a otimização na sua utilização deve acontecer sob um planejamento que satisfaça às necessidades de saúde da população. Como enfatizado por diversos autores, conhecer e entender esse sistema é uma tarefa complexa e multidisciplinar. Nesse sentido, na perspectiva dos pesquisadores da área de saúde coletiva, é importante saber de que maneira podemos contribuir com conhecimentos que levem ao aperfeiçoamento e regulação deste sistema. Sendo assim, as funções da gestão orçamentária necessitam de avaliação segundo sua integração, deixando claro o fluxo contínuo do planejamento até a avaliação, produzindo os resultados esperados nos serviços de saúde. Nos debates sobre justiça distributiva vêm sendo propostas várias regras alocativas, a regra alocativa 
é um conjunto de instruções que articulam variáveis para decidir como uma alocação de recursos deve ser feita, na maioria das vezes essas regras alocativas utilizam indicadores de saúde, na tentativa de encontrar uma solução para o desafio imposto pelo envelhecimento populacional. Objetivo: o objetivo do trabalho foi identificar como os indicadores básicos de saúde do idoso têm sido usados no processo de alocação de recursos. Ainda, analisar quais indicadores são utilizados para construir políticas públicas no âmbito da saúde do idoso. Métodos: para cumprir os objetivos, foi realizada uma revisão integrativa da literatura. A revisão integrativa é um método que proporciona a síntese de conhecimento e a incorporação da aplicabilidade de resultados de estudos significativos na prática. A revisão integrativa permite a inclusão de estudos experimentais e não-experimentais para uma compreensão completa do fenômeno analisado. Combina também dados da literatura teórica e empírica, além de incorporar um vasto leque de propósitos: definição de conceitos, revisão de teorias e evidências, e análise de problemas metodológicos de um tópico particular. A pergunta norteadora para busca das evidências foi: como os indicadores básicos de saúde do idoso têm sido usados no processo de alocação de recursos? Dando prosseguimento ao o levantamento dos artigos na literatura, realizou-se uma busca na BIREME (Centro Latino-Americano e do Caribe de Informação em Ciências da Saúde), e foram utilizados os seguintes descritores: indicadores de saúde; saúde do idoso; e alocação de recursos. A sintaxe da busca foi a seguinte: (tw:((tw:(alocação de recursos)) $A N D$ (tw:(saúde do idoso)))) $A N D$ (tw:(indicador de saúde)). Os critérios de inclusão definidos para a seleção dos artigos foram: artigos publicados em português, inglês e espanhol, artigos na íntegra que abordassem a temática referente aos indicadores básicos de saúde do idoso usados no processo de alocação de recursos. Não houve restrição de período de busca e foram excluídos trabalhos na modalidade de pesquisa bibliográfica, revisões, monografias, teses, dissertações. Resultados preliminares: ao realizar a busca com os critérios de seleção foram encontrados 110 artigos nas bases de dados selecionadas, desses apenas 43 disponibiliza o texto completo, mas apenas 37 textos estão nos idiomas que poderão ser pesquisados. $\mathrm{Na}$ primeira análise feita pelos títulos não se verificou duplicidade de textos, portanto a próxima etapa será analise dos resumos, seguida de leitura na integra dos artigos selecionados. Considerações finais: espera-se sintetizar artigos que pesquisaram como foram direcionadas as alocações de recursos para a criação de políticas públicas que prestigiem a saúde do idoso, na sua integralidade, se possível utilizando os indicadores de saúde como ferramentas norteadoras, garantindo acesso e inclusão dessa parcela da população.

Descritores: Indicadores Básicos de Saúde; Saúde do Idoso; Alocação de Recursos. 